\title{
Un paso más hacia la bacteriemia cero
}

\author{
Isabel Crehuet Rodríguez, María Albina Bernárdez Lemus, Marta Ramírez Crehuet, Pilar Méndez Briso- \\ Montiano, Carlos Ruiz-Zorrilla López
}

\section{Hospital Universitario Río Hortega. Valladolid}

\section{Introduccion:}

El número de catéteres venosos centrales tunelizados (CVCT) para hemodiálisis (HD) ha aumentado tanto que suponen casi el $50 \%$ de los accesos vasculares. Esto conlleva a un mayor número de complicaciones, entre las que destacan las infecciones por su gravedad y los costes que ello genera. De ahí la importancia de su prevención.

\section{Objetivos:}

1. Estudiar los índices de bacteriemia relacionada con el catéter (BRC), en nuestra unidad, durante 800 días: 400 aplicando el protocolo de la unidad y 400 utilizando además unos bioconectores especiales para el catéter de HD.

2. Comparar estos índices y valorar la eficacia de dichos bioconectores.

3. Identificar los gérmenes más frecuentes y analizar la incidencia de Staphylococcus Aureus en las BRC.

4. Valorar el papel de Enfermería en la obtención de estos Índices.

\section{Método:}

Hemos hecho un estudio observacional, retrospectivo, transversal del índice de BRC durante un periodo de 800 días: 400 aplicando nuestro protocolo (asepsia + frotis nasales seriados) y 400 utilizando además los bioconectores. Comparamos los resultados, analizando el mismo número de días en ambos periodos para evitar sesgos y objetivar mejor la eficacia de dichos conectores. Nuestro protocolo consiste en la manipulación del catéter siguiendo las medidas universales de asepsia y frotis nasales a los pacientes cada 6 meses. Consideramos BRC la aparición de fiebre con hemocultivos positivos sin otro foco de infección. Si fiebre: hemocultivos y tratamiento antibiótico empírico y si ésta persiste retirada del catéter. No antibioterapia profiláctica previa a la inserción y sellado con sustancias anticoagulantes. Recambio de bioconectores una vez por semana. Incluimos a todos los pacientes portadores de CVCT para HD. En el primer periodo estudiamos 24 pacientes $(n=24)$; de ellos excluimos 5 en el segundo por usar FAVI. Los 19 restantes se estudiaron también en el segundo periodo al que se añadieron 6 nuevos, sumando 25 pacientes $(n=25)$. El análisis estadístico se realizó con los programas SPSS 15.0 para Windows y el programa EPIDAT 3.0 (estadísticamente significativa si $p<0,05$ ).

\section{Resultados:}

PRIMER PERIODO: 24 pacientes: 10 mujeres y 14 hombres; media de edad 68,79 $\pm 15,14$; mediana del tiempo en HD de 44,5 meses rango $(28,75-67,25)$; lugar de inserción: 19 en vena yugular derecha, 4 en yugular izquierda y 1 en femoral izquierda; $n^{\circ}$ de infecciones con hemocultivo positivo: 4 producidas por: Streptococcus Gram+ Kokuria Cristinae, Streptococcus Sanguinii, Gemella Morbilliorum y Staphylococcus Coagulasa negativo. $\mathrm{N}^{\circ}$ total días-catéter: 7062 . Índice de bacteriemia: 0'56/1000 días-catéter.

SEGUNDO PERIODO: 25 pacientes: 10 mujeres y 15 hombres, media de edad 70,44 $\pm 14,27$; mediana del 
tiempo en HD de 29 meses rango (17-67); 18 catéteres en vena yugular derecha, 4 en izquierda, 2 en femoral derecha y 1 en izquierda; $n^{\circ}$ de infecciones con hemocultivo positivo: 2 producidas por Enterobacteria (E.Coli) y Staphylococcus Coagulasa Negativo. $\mathrm{N}^{\circ}$ total días-catéter: 8622. Índice de bacteriemia: 0,23/1000 días-catéter.

\section{Discusion y conclusiones:}

Enfermería tiene un papel fundamental en conseguir estos índices. Reducción del $50 \%$ en tasas de BCR con bioconectores. No BRC por S. Aureus, mayor frecuencia por E. Coagulasa.

\section{Referencias Bibliográficas}

1. Rodríguez Hernández JA, Gutiérrez Julián JM. Catéteres venosos centrales. Guías de acceso vascular en hemodiálisis. SEN 6: 116-166, 2004.

2. Registro Español de Enfermos Renales. Informe 2006 de diálisis y trasplante renal en España. Nefrología 29: 525-533, 2009.

3. National Kidney Foundation. KDOQI Clinical Practice Guidelines and Clinical Practice Recommendations for 2006 Updates: Hemodialysis Adequacy, Peritoneal Dialysis Adequacy and Vascular Access Am J Kidney Dis 2006; 48 (suppl 1): S1-S322.

4. Beathard GA, Urbanes A. Infection associated with tunneled hemodialysis catheter. Semin Dial 2008; 21: 528-38.

5. Albalate $M$, Pérez García R, De Sequera P, Alcázar R, Puerta M, Ortega M, Mossé A, Crespo E.
¿Hemos olvidado lo más importante para prevenir las bacteriemias en pacientes portadores de catéteres para hemodiálisis? Nefrología 30 (5): 573-7, 2010.

6. http://www.victus.com/esp/products/conector-tego/ medical-conector-tego.html.

7. Martínez Aranda MA, Arribas Cobo P, Ruiz Álvarez A, Rodríguez Estaire J, Callejo Cano I, Díaz de Argote P, Sáenz Santolaya A, Cerrajero Calero $R$, Liébana Pamos B, Guimerá Ferrer- Sama MA, Larico Cuno M, Quesada Armentero MT, Herrera Martín E, Vinagre Rea G, García Estévez S. Eficacia del uso de bioconectores para los catéteres centrales de hemodiálisis. Rev Soc Esp Enferm Nefrol 2011; 14 (2): 106/111.

8. Cobo Sánchez JL, Sainz Alonso RA, Vicente Jiménez MY , Cepa García H, Pelayo Alonso R, Menezo Viadero R, Ibarguren Rodríguez E, Pérez GarmiIla AI, Rojo Tordable M, Begines Ramírez A, Sola García MT, Alonso Nates R. Estudio comparativo de incidencia de bacteriemias relacionadas con el catéter de hemodiálisis: bioconectores frente a conexión directa. Rev Soc Esp Enferm Nefrol 2011; 14 (4): 230/235.

9. Mc Afee N, Seidel K, Watkins S, Flynn JT. A continuous quality improvement project to decrease hemodialysis catheter infections in pediatric patients: use of a closed luer-lock access cap. Nephrol Nurs J. 2010; 37(5): 541-4.

10. Crehuet Rodríguez I, Pilar Méndez Briso-Montiano P. Supervivencia de un catéter: un reto y un logro de enfermería. Rev Soc Esp Enferm Nefrol 2011; 14 (3): 189-194. 